\title{
Transportation Bipolar Ni-MH Battery
}

\author{
Martin G. Klein*, Michael E. Reed*, James T. Landi*, Robert F. Plivelich*
}

A novel bipolar packaging design for a nickel metal hydride (NiMH) battery has been developed. As with other bipolar designs, advantages include reduced battery resistance and volume when compared with more conventional approaches. These advantages make the bipolar NiMH an excellent energy and power source for existing and emerging high voltage, high power applications. In this paper, we give an account of our recent experiences with the design, with a focus on designs for high power batteries for hybrid electric vehicles and high energy batteries for plug-in hybrids. In addition, we discuss results from a hybrid electric vehicle to plug-in hybrid electric vehicle conversion utilizing a high energy bipolar NiMH battery. The conversion and results demonstrate the successful implementation of the battery design in an automotive application.

Keywords: Nickel Metal Hydride (Ni-MH), Battery, Electric Vehicles, Hybrid Electric Vehicles, Plug-In Hybrid / Grid-Connected HEV

\section{INTRODUCTION}

As the cost of oil based fuels continues to rise, and the concerns of the environmental effects from burning such fuels grow, alternative means of energy are being explored for the transportation industry. Governments and individual consumers are demanding cheaper and cleaner sources of energy to power small and large consumer vehicles, as well as public transportation vehicles. One such means of supplying this energy is through energy storage such as rechargeable batteries. These can be used in multiple transportation applications, including electric bikes and scooters, hybrid electric vehicles (HEVs), plug-in hybrid electric vehicles (P-HEVs), and various configurations of electric buses.

However, it has always been believed that these advanced vehicle applications could not be implemented into widespread production because of the limitations of the available battery technologies, which are said to be too heavy and too large. Electro Energy's bipolar battery design differs from these conventionally available designs in that it results in a smaller and lighter battery for these applications.

\subsection{Battery Design Alternatives}

Conventional battery designs include cylindrical and prismatic types. A bipolar battery is one in which both a positive and a negative electrode are in contact with a conductive partition. As is readily apparent in Figure 1, a bipolar battery's most attractive attributes involve the reduction of the current path through the electrodes, as well as potentially simplified battery manufacturing. The reduced current path leads to a design that has lower internal resistance, with the capability of supplying much

* Electro Energy, Inc., 30 Shelter Rock Road, Danbury, CT 06810, e-mail: mklein@electroenergyinc.com; mreed@electroenergyinc.com; jlandi@electroenergyinc.com; rplivelich@electroenergyinc.com. higher power levels. However, most attempts at designing bipolar secondary batteries have suffered from the problems of electrolyte leakage and management of gas pressure within the cells. Table 1 provides a brief overview of the relative advantages and disadvantages of various battery design approaches.

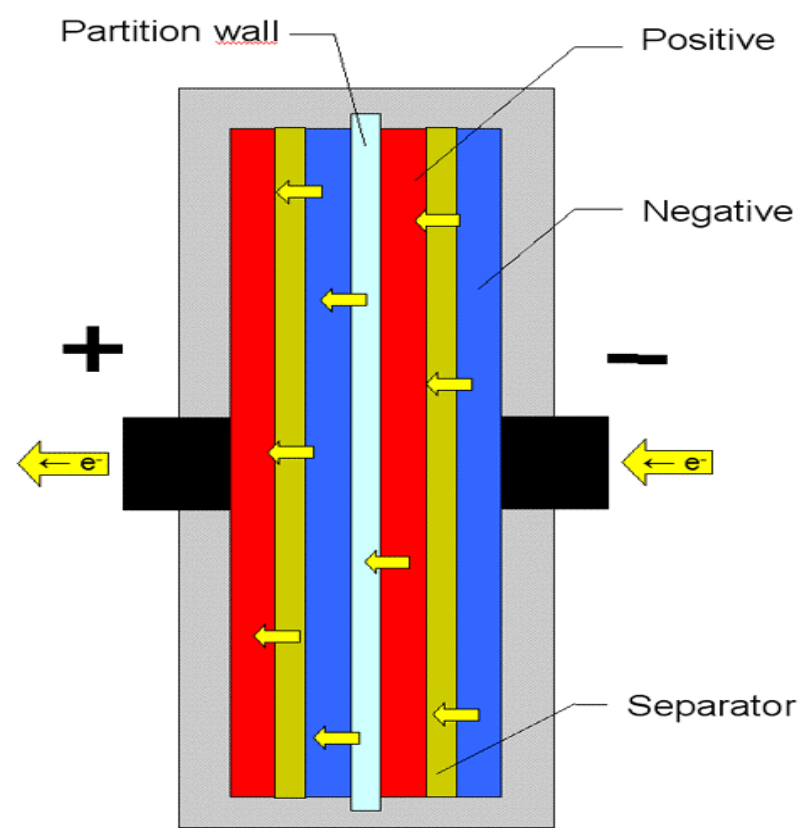

Fig. 1 Schematic of a bipolar battery. 
Table 1 Comparison of battery designs.

\begin{tabular}{|c|c|c|}
\hline $\begin{array}{l}\text { Battery } \\
\text { type }\end{array}$ & Advantages & Disadvantages \\
\hline Cylindrical & $\begin{array}{l}\text { Well understood } \\
\text { manufacturing } \\
\text { Very robust with } \\
\text { respect to cell } \\
\text { pressure }\end{array}$ & $\begin{array}{l}\text { May not easily } \\
\text { scale to large cell } \\
\text { capacity } \\
\text { Collector losses } \\
\text { Numerous cell } \\
\text { interconnections } \\
\text { Packing } \\
\text { inefficiency }\end{array}$ \\
\hline Prismatic & $\begin{array}{l}\text { Efficient packing } \\
\text { Better scaling to } \\
\text { large capacity }\end{array}$ & $\begin{array}{l}\text { Collector losses } \\
\text { Numerous cell } \\
\text { interconnections } \\
\text { Less robust with } \\
\text { respect to cell } \\
\text { pressure }\end{array}$ \\
\hline Bipolar & $\begin{array}{l}\text { Efficient packing } \\
\text { Reduction of } \\
\text { collector losses } \\
\text { (reduced } \\
\text { resistance) } \\
\text { Simplified cell } \\
\text { interconnection }\end{array}$ & $\begin{array}{l}\text { Electrolyte leakage } \\
\text { Dealing with cell } \\
\text { gas pressure }\end{array}$ \\
\hline
\end{tabular}

\subsection{The Wafer Cell Approach}

Figure 2 shows a schematic cutaway of the bipolar wafer cell. Individual flat wafer cells are constructed with contact faces, one positive electrode, a separator, and one negative electrode. The contact faces are sealed around the perimeter of the cell.

To build multi-cell batteries, identical cells are stacked, one on top of another, positive-to-negative. This results in a series connection of cells. To complete the battery, current collecting contact sheets are placed on the end cells, and the entire stack is held in compression.

A key element of the wafer cell is the use of laminates as the faces of the cell. The laminates consist of a plastic film, a sealant which serves to prevent electrolyte creep, and a metal foil, which serves to conduct the current. When held in compression, this configuration effectively eliminates cell leakage concerns.

Another improvement in the wafer cell approach is the means by which cell pressure is handled. As in other battery designs, control limits are established with respect to battery voltage and temperature. Unlike other designs, however, the thin and flexible construction of the wafer cell allows one to monitor pressure as well.

To keep the control system tractable, groups of cells are monitored as stacks, ranging from $24-48 \mathrm{~V}$ (20-40 seriesconnected cells). If any cell within the group generates significant amounts of gas pressure, it expands. The deflection of the stack caused by this pressure can be sensed by normally-closed spring-loaded switches or by small load cells placed within the battery. The outputs from these switches are used as inputs to the battery control system.

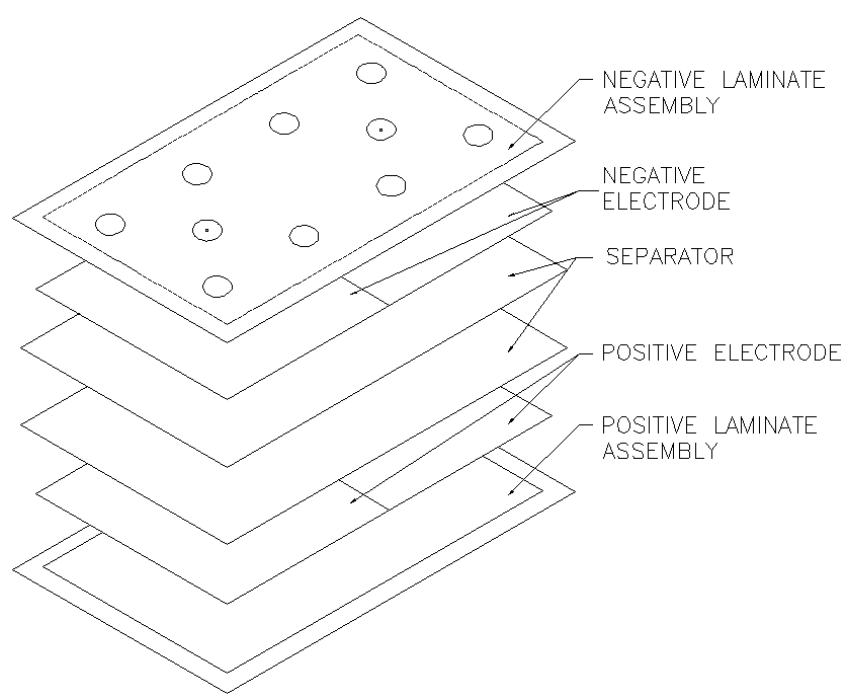

Fig. 2 Wafer cell layout.

We believe that the combination of the wafer cell design coupled with cell pressure sensing ability solves the fundamental issues facing secondary bipolar battery designs. Thus, the bipolar battery is able to serve as a drop-in replacement for existing batteries of various chemistries.

Overall, the unique design leads to the elimination of hardware for inter-cell connections. This results in a battery that can be packaged in a much lower volume, and also costs less, than a conventional battery having similar energy.

\section{APPLICATION TO HYBRID ELECTRIC VEHICLES (HEVs)}

Hybrid electric vehicles (HEVs) are becoming increasingly popular as the cost of fuel rises. HEVs use a high power battery that complements the conventional internal combustion engine, providing added power during acceleration and at other times where the engine is not as efficient. In addition, the HEV recaptures energy normally lost during braking. This results in nearly $33 \%$ better fuel efficiency than conventional vehicles.

The high-power bipolar NiMH battery design lends itself naturally to HEV applications. Currently, we are demonstrating the technology using the Toyota Prius HEV as the test bed.

The OEM battery used in the vehicle utilizes the NiMH chemistry. It is rated at $6 \mathrm{Ah}, 202 \mathrm{~V}$, with approximate dimensions of $29 \mathrm{~cm} \times 60 \mathrm{~cm} \times 14 \mathrm{~cm}$, and total volume of 24.36 L. An image of the battery is shown in Figure 3.

A direct substitute for the OEM HEV battery has been developed using the bipolar approach. The battery consists of two modules connected in series. Each module is rated at $101 \mathrm{~V}, 6 \mathrm{Ah}$, and has dimensions of $17 \mathrm{~cm} \times 34.3 \mathrm{~cm} \times 14$ $\mathrm{cm}$, with a total volume of $8.16 \mathrm{~L}$, and a weight of $19.5 \mathrm{~kg}$. 
The complete HEV replacement, shown in Figure 4, would consist of two (2) modules connected in series, resulting in a battery that has approximately 30\% less volume, and a projected cost that is $25 \%$ less, than the OEM Prius battery.

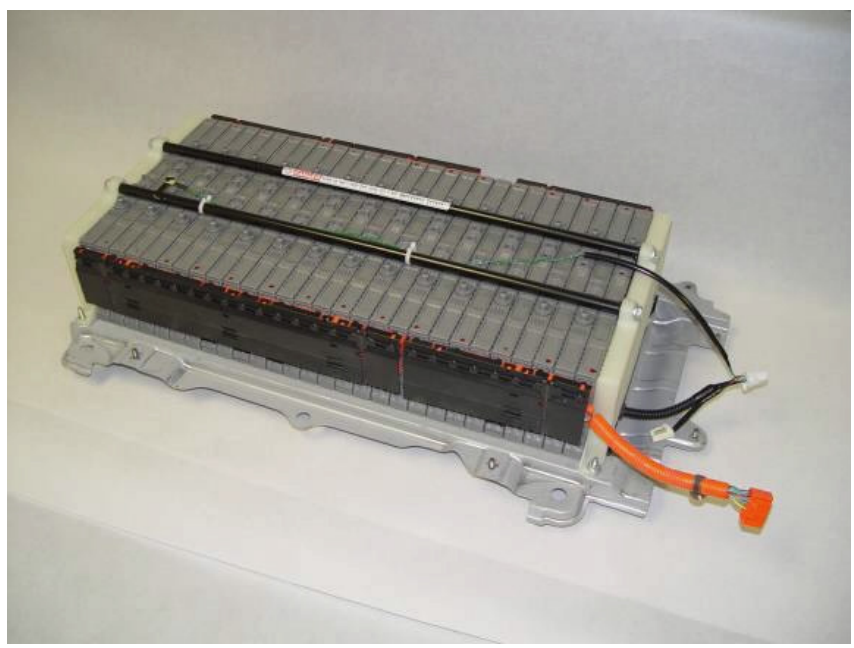

Fig. 3 OEM Prius battery.

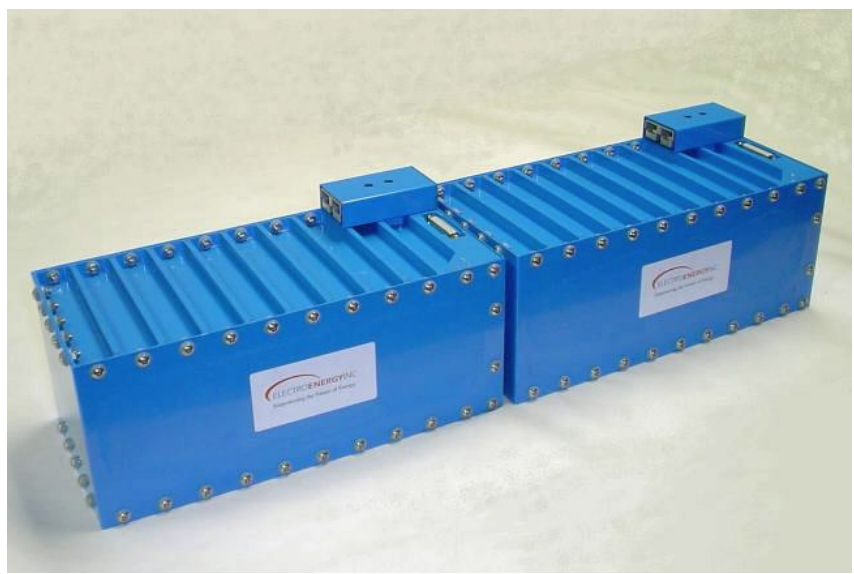

Fig. 4 Prototype bipolar HEV battery.

As of this writing, systems integration efforts are underway to allow the bipolar NiMH battery to interface properly with the Toyota Prius.

Some test data is available which compares the performance of the bipolar battery to the conventional OEM one. Figure 5 shows the results of a simulated HEV laboratory test obtained with a bipolar battery. The battery is operated on a charge neutral cycle: $115 \mathrm{~A}$ discharge for 12.8 seconds, followed by a constant voltage recharge at $250 \mathrm{~V}$ until the $0.4 \mathrm{Ah}$ removed during discharge is returned.

From a systems integration standpoint, the Prius BMS requires the battery voltage to remain higher than $180 \mathrm{~V}$ at all times during normal driving. Figure 5 shows that the bipolar battery meets this criterion, when pulsed at approximately $20 \mathrm{C}$ rates.

As a comparison between the bipolar and OEM HEV batteries, a test profile was run with a $10 \mathrm{~s}, 80$ A discharge, followed by a $10 \mathrm{~s}, 60$ A charge. This profile was run consecutively, as shown in Figure 6, at 90\% and 80\% SOC.
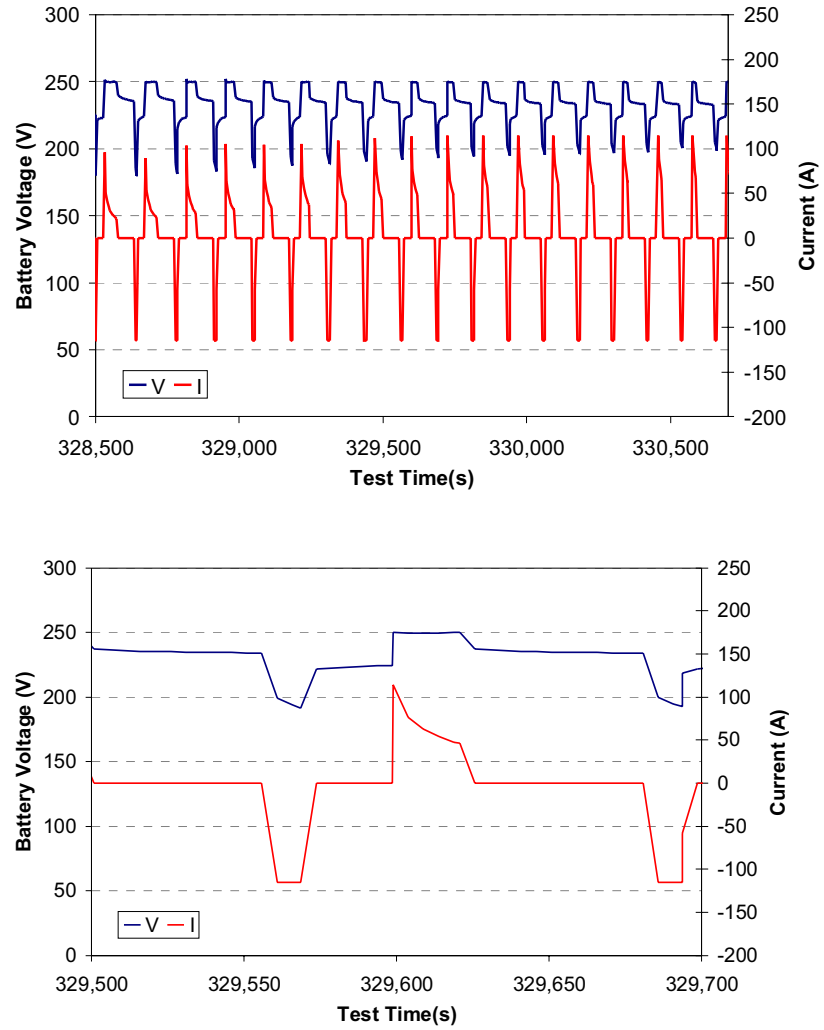

Fig. 5 Pulse cycling of bipolar battery.

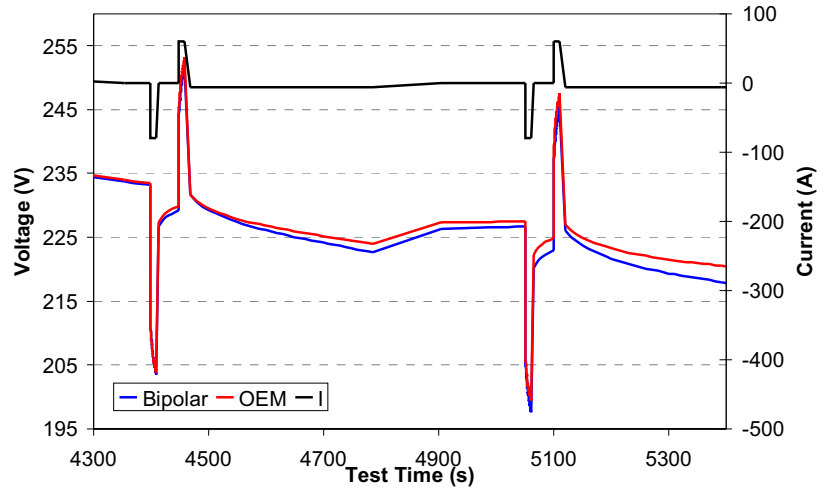

Fig. 6 Comparison of bipolar and OEM NiMH HEV batteries.

It can be seen that the blue voltage trace of the bipolar battery falls right on top of the red OEM trace. The slight spread observed as the test proceeds is the result of the OEM battery having an actual capacity that is about $10 \%$ greater than the bipolar battery. From this data we are able to conclude that the bipolar design results in a battery that has the equivalent performance of the OEM HEV battery, while occupying 30\% less volume. As energy storage requirements increase and volume constraints become tighter, the benefits of the bipolar design will be realized. 


\section{APPLICATION TO PLUG-IN HYBRID ELECTRIC VEHICLES (PHEV)}

To further reduce the fuel consumption, the plug-in hybrid electric vehicle is a concept that is gaining more and more support. A PHEV utilizes a significantly larger battery than an HEV. The goal is to be able to operate for a significant driving range, $30-80 \mathrm{~km}$, on battery power alone. Once the battery is drained, or if there are large load requirements, the car reverts to conventional $\mathrm{HEV}$ mode and uses the gasoline engine as needed. In this way, it is possible to increase the range of a car to twice that of currently available HEVs.

There are two basic ways one can configure plug-in hybrid batteries. The first is that the OEM HEV battery is replaced altogether with a higher energy battery. The excess energy is used to drive the car in all-electric mode until the energy of the replacement battery reaches a level equivalent to the energy of the original OEM battery. At that point, the high-energy battery serves the same function as the original OEM battery. This concept has the advantage of reduced weight, since the OEM battery is physically removed from the vehicle [1].

The second way is that a higher energy battery is connected in parallel with the OEM HEV battery. The high-energy battery essentially maintains the state-of-charge (SOC) of the high power OEM battery, thus allowing the car to remain in all-electric drive mode. This concept has the advantages of increased all-electric drive range, reduced load on the large-capacity battery, and simplified integration with an existing HEV. The disadvantage is that the weight of the original OEM battery remains in the vehicle [1].

Using the Prius as a test bed, we have developed a prototype bipolar battery for the PHEV application. The battery consists of six modules, each rated at $15 \mathrm{Ah}$ and 72 $\mathrm{V}$. The arrangement is two parallel strings, each containing three modules in series. The driving range using this battery is $30-35 \mathrm{~km}$.

Photographs of the battery modules alone and fitted into a Toyota Prius are shown in Figure 7.

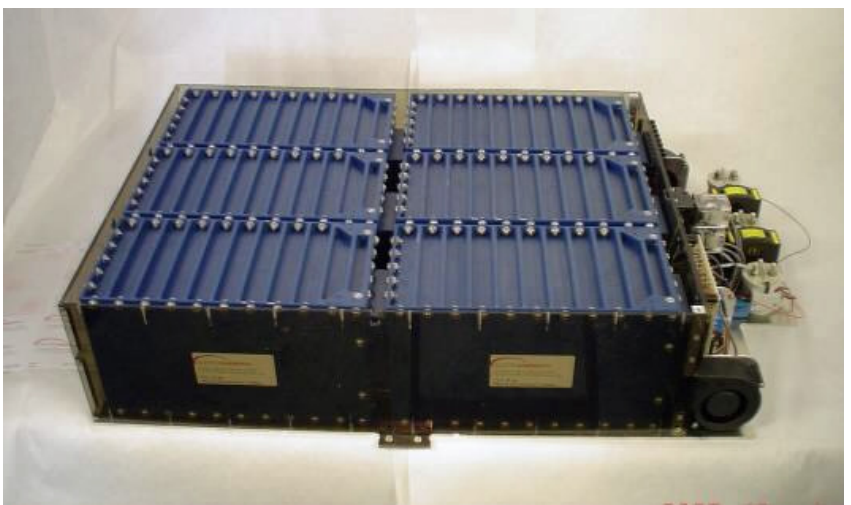

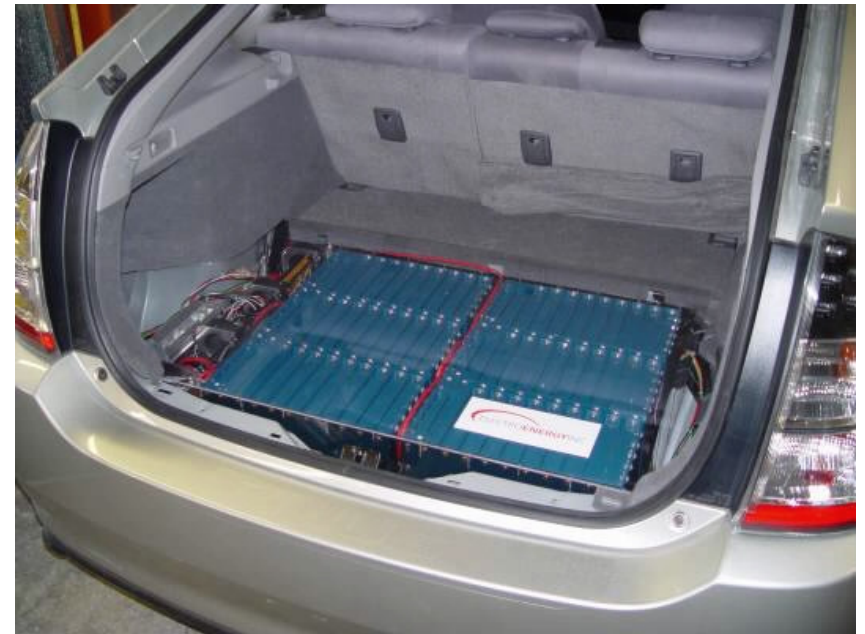

Fig. 7 Bipolar NiMH PHEV battery.

Specifications for the bipolar battery and the modules are given in Table 2.

Table 2 Bipolar PHEV battery specifications.

\begin{tabular}{|l|l|l|}
\hline Parameter & System & Module \\
\hline Voltage & 220 & 72 \\
\hline Capacity (Ah) & 28 & 15 \\
\hline $\begin{array}{l}\text { L X W X D } \\
(\mathrm{cm})\end{array}$ & $54 \times 99 \times 20$ & $17.5 \times 35.25 \times 18.9$ \\
\hline Mass (kg) & $\begin{array}{l}<180 \text { (including controls, } \\
\text { etc). }\end{array}$ & 27.2 \\
\hline
\end{tabular}

In conjunction with the California Cars Initiative for Plug-In Hybrids (www.calcars.org), efforts aimed at developing a plug-in Prius were started in late 2005. The goal was to replace the OEM battery entirely with a larger bipolar one.

At first, we attempted to control our bipolar battery by directly using the OEM battery management system. However, the proprietary nature of the system made this difficult. Ultimately, an interface between our control system and that of the Prius was developed.

After the installation was accomplished, driving data was gathered, with typical data shown in Figure 8. During this drive, the car intermittently drove in all-electric mode, up to 19 kilometers. About 12 Ah net was removed from the PHEV batteries. We believe that control issues were the cause of the relatively short measured range. This conversion and test data represented the successful implementation of the bipolar battery design into a PHEV application. 


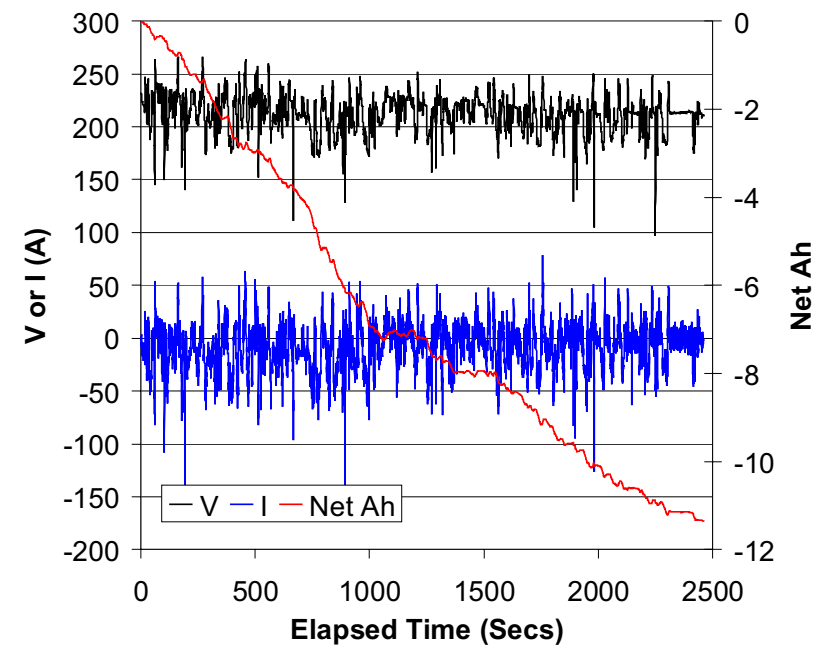

Fig. 8 Performance of the bipolar PHEV battery. Note that the OEM battery was replaced entirely in this configuration.

The next approach was to configure our PHEV battery in parallel with the OEM battery, but only under certain conditions. In this configuration, as the SOC of the OEM battery drops to a preset threshold, the bipolar battery is connected to it. This effectively charges the OEM battery. Once an acceptable OEM SOC has been achieved, the bipolar battery is disconnected. This process is continued until the bipolar battery no longer has sufficient energy to maintain the OEM SOC, at which point the car reverts back to standard HEV operation.

This approach greatly simplifies the integration issues, since the Prius battery management system believes (correctly) that it is drawing all of its energy from the OEM battery. The bipolar battery in this configuration serves only to maintain an acceptable SOC for the OEM battery.

One potential drawback of this scheme is that any regenerative braking current charges only the OEM battery, not the bipolar battery. In reality, this is of little consequence in the majority of driving situations. The only time that regenerative current would be "wasted" would be if the OEM battery was at its maximum SOC and there was still regenerative current available. This scenario would occur in only a few very limited, specific instances.

Under this concept, the prototype bipolar PHEV battery can operate the Prius in an all-electric mode for up to 35 kilometers. Figure 9 shows the battery voltage and current plots for a one hour all-electric Prius trip within a city. It can be seen that under this profile, the maximum load current on the PHEV battery is $40 \mathrm{~A}$, in contrast to the previous configuration, where the battery had to provide high pulse currents of up to $150 \mathrm{~A}$. During this run, the car achieved 32 kilometers of all-electric driving, at $4.5 \mathrm{kWh}$ of energy removed from the batteries. This corresponds to greater than $7 \mathrm{~km} / \mathrm{kWh}$ energy utilization

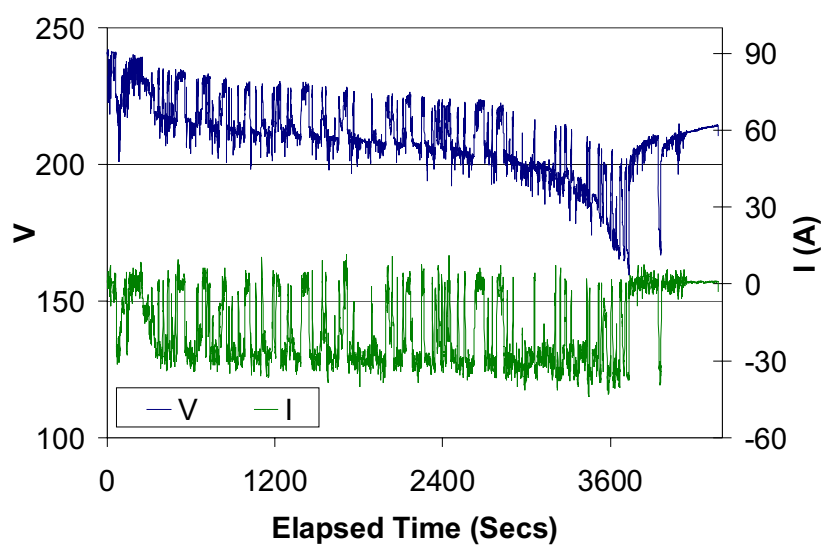

Fig. 9 Bipolar battery data from a 1 hour all-electric drive (Prius test bed).

\section{FUTURE DIRECTIONS}

The authors believe that the usefulness of bipolar NiMH battery technology in a PHEV application has been demonstrated. Planned refinements in the bipolar design are aimed at further reducing weight and volume while increasing range.

In addition, we have adapted the bipolar cell concept to the lithium ion chemistry. Work is ongoing to determine the suitability of bipolar Li-ion for EV / PHEV applications.

\section{REFERENCE}

[1] Robert Plivelich, John Dailey, Lee Huston, James Landi, Martin Klein, The Bipolar Nickel-Metal Hydride Battery for Advanced Transportation and High Voltage Power and Energy Storage Systems, SAE 2006 Power Systems Conference.

\section{BIOGRAPHIES}

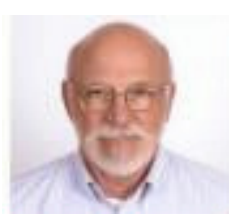

Martin G. Klein, has over 40 years experience in the advanced battery field. He founded EEI in ' 92 to develop and commercialize a concept for bipolar nickel-metal hydride batteries. In 1970, Marty cofounded Energy Research Corporation (now FuelCell Energy) and served as Executive Vice President through 1992. He has authored and coauthored numerous papers, articles and reports and has contributed to three books on battery technology. He is an inventor/co-inventor of 15 U.S. patents and ten foreign patents in the field of advanced electrochemical systems.

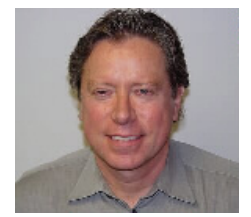

Michael E. Reed, has over 35 years experience in the battery industry in various roles. Prior to joining Electro Energy in May 2005, he served as the Chief Operating Officer of EaglePicher Horizon Batteries, LLC, where he directed the start-up of an advanced technology battery facility in Beijing, China. At Johnson Controls, Mike served as Director of Engineering and then expatriate General Manager of Johnson Controls' South American Battery Operations headquartered in Sao Paulo, Brazil. Before that, Mike held several technical, operations and general management positions within Exide Corporation and the Delco Remy Division of General Motors Corporation. Mike holds a BSChE from Purdue University and a MBA from Indiana University. 


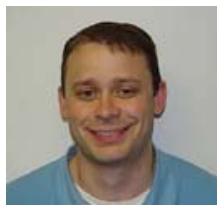

James T. Landi, is the project and engineering manager of Electro Energy's battery development and production scale-up programs, and has been with the company for six years. Prior to joining EEI, Mr. Landi worked for four years as the principal technical investigator for the R\&D of advanced metal hydride battery alloys for a leading specialty chemicals company. Mr. Landi graduated from Rutgers University with a B.S. in chemical engineering.

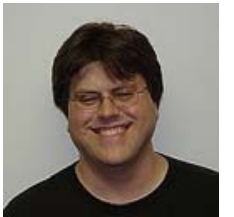

Robert F. Plivelich, has been involved with the development of many aspects of bipolar battery technology at EEI for the past decade. Author or coauthor of numerous papers and several patents related to the technology, he holds a BS degree from the University of Pittsburgh, and an MS degree from the University of California at Berkeley, both in chemical engineering, and an MBA from Western Connecticut State University. 